\title{
A Definição Brasileira
}

Discurso pronunciado pelo Professor João Pinheiro Neto, Oficial de Gabinete do Presidente da República no Auditóíio do Ministério da Educação e Cultura, no dia 16 de julho de 1959, na qualidade de paraninfo do Curso Intensivo, da Escola Brasileira de Administração Pública, da Fundação Getúlio Vargas.

\section{$M_{\text {eus amigos : }}$}

A extrema generosidade de vocês transformou o modesto professor de ontem no austero paraninfo de hoje, com a grave incumbência da última lição e do primeiro conselho.

Que lição seria esta, meus amigos, capaz de sintetizar nestes derra deiros momentos de alegre e fraternal convivência tôdas as idéias que juntos reafirmamos, tôdas as esperanças que vimos como que por milagre se reacenderam nos nossos corações, empenhados que estávamos, professor e alunos, na busca tenaz e incessante da verdade. Só isto realmente nos preocupou. Não se tratava de ensinar adolescentes imaturos, que apenas ensaiassem afoitos e deslumbrados os primeiros passos na vida. Não se tratava de evitar desilusões e desencantos. Não cogitou nunca o Professor de fantasiar com côres mais sugestivas a realidade, por vêzes dolorosa, não imaginou caminhadas amenas e suaves, não disfarçou nunca a gravidade dos probremas. Mas, se não foi sonhador, fantasista e lírico, também não aterrou ninguém com perspectivas sombrias, pessimistas e desalentadoras. Procurou apenas, com clareza e objetividades, descer ao fundo das coisas, preocupado, sempre, muito mais com as causas do que com os efeitos.

Juntos aprendemos a não aceitar as explicações convencionais, as idéias fixas, as citações de efeito, as demonstraçốes cabotinas de eruditismo ultrapassado, aprendemos a desprezar os aflsos profetas, os homens das fórmulas maáguinas, das posturas graves e messiânicas, certos que estamos de que a única fórmula realmente eficiente é a do trabalho honrado, assessorado pelo conhecimento técnico adequado.

Percebemos com clareza que a origem dos problemas está em nós mesmos, na nossa imensa fraqueza, nas seduções das vaidades improdutivas, na dispersão com que nos atiramos à luta, preocupados com detalhes inócuos, vazios de ideal, carregando o pesado fardo das nossas decepções e dos nossos infindáveis desalentos. Não teremos paz nas nossas relações, paz no lar, ou no trabalho, se não a obtivermos dentro de nós mesmos, harmonizando 
de modc fecundo as fôrças intimas do espirito, capazes sòmente elas de assegurarem a serenidade e a segurança dos nossos dias. Não há circunstâncias permanentemente desfavoráveis na vida de ninguém. Há erros e equívocos permanentemente repetidos por fôrça de uma precária compreensão da verdade.

Mas, em todos os momentos, por piores que sejam, podemos e devemos lançar sempre mão da nossa inteligência e da nossa fôrça de vontade. Querer é realmente poder, mas é preciso ter critério e bom senso para saber querer, para decidir com sensatez e equilibrio, optar com firmeza e, uma vez decidido, ter fôrça e coragem para não recuar. A vida é um permanente processo de escolha. Até morrer, a todo o momento, a tôda hora, estamos sempre decidindo, sem nunca parar. Os que tentam fugir a essa convocação permancnte são impiedosamente triturados, mas, para os que têm fôrça e capa cidade estão reservados os prêmios e as bênçãos da existência.

Tudo isto aflorava à nossa mente e aos nosso corações, fazendo-nos vislumbrar, por entre a névoa espessa, os primeiros clarões de luz. E, mestre e discípulos, irmanados pelos mesmos ideias, cheios de entusiasmo, renovam a fè a crença na verdade. Porque realmente o que o professor transmite e espera receber é, antes de tudo, entusiasmo. Entusiasmo e um pouco da nossa alma povoada de sonhos e de ideais. Dividimos com vocês as nossas inquietações e as nossas esperanças, certos de que elas se renovarão neste contacto fecundo e generoso, e voltarão a nós como penhor único da sinceridade e da pureza da nossa pregação.

Assim como a curiosidade dos nosso pais e dos nosso avós estava voltada para outras matérias, para o direito, para a medicina ou para a engenharia, a nossa curiosidade, atendendo os reclamos urgentes do país, vol tou-se agora para o problema da administração pública.

Quando o Brasil se libertou de Portugal, depois de uma dependência de três séculos, em que estivemos amarrados a uma forma estreita de colonialismo primário, deplorável e melancólico era o panorama da vida politica, social e econômica no Brasil.

Nenhuma atividade produtiva se havia criado no país, a não ser a da agricultura de exportação. Passando da cana-de-açúcar para o café, para o cacau, para o lgodão, de um modo ou de outro, ssentávamos as bases econômicas da nossa existência no trabalho rural, na monocultura e na escravidão. Feita a independência, nós que herdamos dos portuguêses uma organização política e administrativa do império romano, sentimo-nos de uma hora para outra inteiramente desaparelhados. Portugal não servia como modêlo, as transformações politicas que varreram a Europa, no fim da idade média e no comêço dos tempos modernos, quase não afetaram a nação lusitana.

Sob o ponto-de-vista dos métodos administrativos e da estrutura jurídica mais adequada, estávamos inteiramente desorientados. Com D. Pedro I, figura curiosa, com toques geniais, dentro das contradições absurdas de sua perscnalidade, tivemos o Brasil romântico e aventureiro. A instabilidade 
psiquica de D. Pedro I, aliada à sua pouca cultura intelectual, não poderia permitir que a nação jovem, que iniciava seus primeiros passos, tivesse diante de si rumos firmes e bem delineados. Não havia nenhum plano a longo prazo, em que se iniciasse, com perseverança e tenacidade, a conquista do pais. De qualquer maneira, D. Pedro I, além de ter-nos feito independentes, n) que é mais importante, consolidou a independência e assegurou a unidade da pátria.

D. Pedro II, a quem foi entregue um país jovem, sedento de progresso e de transformações, ansiando por um estadista autêntico que lhe entendesse as dificuldades e que, jovem como êle, tivesse a coragem e o gôsto de desafiar o futuro, não foi a solução ideal de que necessitàvamos. Figura pacata de burguês tranquilo, letrado e professoral, por certo teria trocado as agruras da chefia de um Império, em que tudo estava por se fazer, for uma cadeira de Historia e Geografia, do Colégio Pedro II.

Incentivador das artes em um pais de escravos e analfabetos, deliciava-se D nosso Imperador com os concursos de oratória a que assistia atento, com os belos espetáculos da Ópera a que prestigiava com sua presença e com seu apoio irrestrito. Por tôda parte floresciam os talentos poéticos e artísticos, o padre José Maurício e Carlos Gomes eram os heróis nacionais, venerados e consagrados pelo povo. Essa ênfase que se dava ao problema artístico e intelectual, agravada por herança portuguêsa histórica, deu ao Brasil um aspecto singular. Desenvolveu-se nas nossas elites uma preocupação excessiva com o problema jurídico, com os aspectos formais, com os gorjeios oratórios de grande efeito sonoro, mas de nenhum sentido prático. Criou-se um jurisdicismo superafetado e pedante e, estimulado pelo regimen parlamentarista, copiado da Inglaterra, o pais se entregou inerme aos caprichos e às limitações do bacharelismo gongórico, pedante e artificial.

Nenhuma atenção se dava ao problema econômico, social ou administrativo. Um sistema unitário inadequado às nossas características, emperrava o desenvolvimento do país, dificultando, deformando e atrasando a realização do seu destino. O parlamentarismo, uma das ficções jurídicas que criamos, nunca funcionou com autenticidade, as eleições eram fraudadas e o poder moderador era realmente o ditador sutil que alterava, a seu talante, a composição da cena politica, fazendo entrar êsse ou aquêle figurante que dòcilmente se submetia aos caprichos e aos desejos imperiais.

E assim vivia o nosso Brasil: na côrte o brilho das palestras agradáveis e eruditas, a oratória fluente, o estilo castigado, o culto da língua, o amor à forma e a paixão do belo. No interior o abandono total. A miséria descontiecida dos políticos e das elites enfatuadas que, com zêlo exemplar, discutian os inalienáveis direitos do homem, os fundamentos filosóficos da liberdade, ou a infalibilidade do Papa. Mas, de saúde, de educação e de desenvolvimento econômico, em têrmos de penetração e de conquista do interior, ninguéh ousava falar. Absorvidos por discussões bisantinas aguardavam os nossos letrados ilustres, com avidez, o momento de arrumar as malas e pegar o navio que os levaria ao velho mundo, donde, com displi- 
Cência e ceticismo, enviavam, vez que outra, nostálgicas mensagens à terra inóspita e primitiva, que tão longe ficara, e sequiosos se aprestavam a novas tertúlias literárias nos cafés de Paris e adjacências. Dessas viagens periódicas voltavam mais crentes das maravilhas européias, e mais desiludidos ainda das possibilidades nativas. De lá, do velho mundo, trouxeram o parlannentarismo e vestiram com êle o Brasil. Tinha que dar certo, pois não deu certo na Inglaterra adiantada, culta e educada? Por que não serviria para nós?

E' claro que não poderia servir. $E^{\prime}$ claro que os nossos problemas eram e são outros, é lógico que um sistema político deva ser o reflexo da cultura de cada povo, da sua realidade social e econômica, e nunca um figurino pré-fabricado, meia-confecção comprada no varejo das velhas nações. Se fôsse assim, não haveria problemas jurídicos nem sociais. O que deu certo ali, deveria também funcionar aqui, seria apenas transplantar a jdéia c deixar que ela, milagrosamente, criasse e acelerasse o progresso.

Mas, infelizmente, a coisa não é tão simples. Não podemos importar sistemas politicos, juridicos ou administrativos.

Os E. U. da América do Norte, quando proclamaram a sua independência. criaram um sistema político próprio que atenderia às suas necessidades e aos seus desejos. Nós, não. Simplesmente adaptamos um sistema político ao nosso país. E fomos buscar o exemplo e a inspiração em uma nação sem nenhum ponto de contacto com a nossa, por incrivel que pareça, diametralmente oposta ao que somos e ao que éramos, como povo e como terra.

E o legado de mais essa importação foi acentuar as deformações básicas do nosso temperamento, estimulando o gôsto pela oratória, pelas soluções juridicas, incentivando no brasileiro o parnasianismo político, que foi a preocupação constante dos homens públicos do Império. Com tal fôrça atuaram essas tendências e essas inclinações que até os dias de hoje, a grande preocupação das elites nacionais era, antes de tudo, de ordem estética. A aparência bem posta e harmonizada das coisas, as soluções de fachada e nunca o sentido ético da vida, ético como sinônimo de justo, de decente e de digno, sob o ponto-de-vista econômico e social. Contornavam-se os problemas lhes atirando um manto perfumado e ricamente enfeitado, mas, sob aquela aparência harmoniosa e bela, agitava-se aflito, desesperançado e abandonado, um povo jogado à sua própria sorte.

Com a República a coisa não se alteraria em profundidade. O novo regimen se faria meio por acaso, produto das desavenças militares, das consequiências da guerra do Paraguai e da abolição da escravatura. A adesão das principais figuras monárquicas foi inevitável, mas, ainda que isto não se desse, os republicanos autênticos não teriam fôrças para evitar - abastardamento do novo regimen que, como o antigo, já vinha eivado de contradiçôes, de incoerênciaş e de vícios lamentáveis. A mesma mentalidade teria que predominar. As mesmas preocupações, a mesma inadequação à nossa realidade, a mesma tentativa, já demonstrada falha, de se 
conseguir, através de um movimento de cúpula, transformações de base capazes de atender às verdadeiras exigências da nação. O movimento republicano passou despercebido inteiramente à grande maioria da população que vivia às voltas com o problema, não tão simples da sobrevivência material, com as questões graves do analfabetismo, das condições de higiene, das garantias do trabalho, do amparo à produção, enfim, de uma possibilidade efetiva de melhoria de vida para todos. Convenhamos, neste caso, não seria nada fácil atrair alguém para questões tão complexas como a da federação, habeas-corpus, liberdade de expressão. Afinal, para aquêle mundo, de cogitações jurídico filosóficas em que vivia a nossa elite desatualizada. Algumas vêzes assombrávamos o mundo defendendo com brilho inexcedivel, nas mais altas tribunas da terra, a igualdade juridica das nações, quando muito mais útil seria se tôda essa cultura e tôda essa inteligência tivesse sido colocada a serviço da igualdade jurídica do brasileiro, igualdade jurídica com substância econômica, sem o que, até a federação se transformaria, como se transformou em mais uma imaginosa articulação mental a serviço das ilusões e das fantasias criminosas dos nossos dirigentes.

Mas, nem sempre poderia durar aquêle estado de coisas. A revolução industrial teria que chegar até nós abrindo para o povo brasileiro as mesmas perspectivas, que já abrira para outros povos. E, sob a estrutura jurídica inadequada que pretendia nos abrigar, começam a se agitar as esperanças populares, açuladas pelos ventos novos que sopravam. E as elites foram chamadas a uma definição. Pouco importa que fôssemos presidencialistas, como ontem ármos parlamentaristas, que fôssemos uma federação, que o nosso créditc no exterior fôsse bom, a nossa moeda respeitada e os nossos débitos resgatados com sistemática e honrada pontualidade. $O$ fato é que éramos pobres, o fato é que não aproveitávamos as riquezas do país, que viviamos mal, sem confôrto e sem dignidade. O fato é que não era possível continuar assim, e se deu a mudança há tanto esperada.

Como decorrência das revoluções sociais que varreram o mundo, como decorrência da certeza que tem hoje o homem, de que pode e deve ser feliz na terra, como decorrência do extraordinário avanço da técnica e da ciênicia, abriram-se novos horizontes para a humanidade.

No Brasil o Estado teria que deixar de ser aquêle cenáculo ilustre de intelectuais diletante spara se transformar, por exigência da época em que vivemos, numa trincheira de luta pelo desenvolvimento social e econômico de nossa terra. Não nos cabe discutir se esta intervenção é boa ou má. Ela não se deu porque o desejassem nossos homens públicos, ou porque esta ou aquela doutrina o determinasse. Desta vez, sim, atendemos aos apelos da realidade. A intervenção do Estado, fato corriqueiro na história política dos nossos dias, é um imperativo de sobrevivência na vida das nações pouco desenvolvidas.

Cresceram de tal modo as exigências populares, aumentaram tão vertiginosamente o vulto dos problemas, que só o poder público é capaz de recrutar os capitais necessários aos investimentos econômicos de larga en - 
vergadura, capazes de garantir uma infra-estrutura material estável a tôdas as nações do mundo. Não se trata de combater a livre iniciativa, trata-se de entender o problema, aceitando a solução que o bom senso indica e a realidade impóe. Quando as exigências eram menores, a população do mundo mais reduzida, mais conformada e dócil, era possivel pensar em têrmos modestos, quando se cogitava de custear empreendimentos públicos. Mas, hoje, a coisa é bem diferente. Não seria esta frágil estrutura juridica que ai está, como que condenada à morte, sentindo já os passos do carrasco que iria sufocar os reclamos coletivos que exigem a intervenção do Estado, como penhor da disciplina da vida financeira e do estimulo ao desenvolvimento econômico, única saída autêntica para as aflições crônicas que nos afligem.

Só se ilude quem quer. Já estaríamos mergulhados no cáos, na desordem ou na ditadura, se o Estado, platônicamente, tivesse se afastado do campo da luta. Não tenham dúvidas, uma boa e justa legislação social e um desenvolvimento econômico sadio representam fator de tranqüilidade social indiscutivel, muito mais eficiente do que qualquer Constituição imprrtada, do que qualquer sistema político que indubitàvelmente tem a aparência, a substância e o destino que as fôrças econômicas e sociais do país lhe atribuirem.

Não podemos vacilar mais um momento sequer.

A intervenção do Estado é ưn fato consumado. E' preciso agora adaptar o regimen político às circunstâncias novas que se projetaram na vida nacional, fazendo o eficiente e honrado a serviço dos interêsses da maioria. A República velha está enterrada definitivamente, e o espaço para a nova ai está, esperando que o patriotismo das nossas elites crie, com inteligência e objetividade, o instrumento mais adequado aos reclamos do nosso desenvolvimento. A democracia, meus amigos, não é um sistema jurídico nem um regimen político, a democracia é, antes de tudo, uma forma de viver, de respeitar os direitos alheios, de garantir aos mais humildes o acesso às fontes de estudo e de trabalho, de dar a todos a garantia de uma vida decente e digna. Mas, esta forma de viver só tem existência duradoura se contar com o apoio e a solidariedade do povo que, dela se benefiando, por ela será capaz de dar a própria vida. Mas, se ao contrário, a vida democrática, ratificando privilégios e sancionando injustiças, criar a República de alguns para muito poucos, em que muitos são os que dela se servem, sendo pouqu"ssimos os que por ela são servidos, estaremos irremediàvetlmente perdidos e ninguém nos salvará do desastre final.

O país não acredita mais que possamos ser ricos por mercê de Deus, o ufanismo lírico de ontem se transformou, por completo. Estamos certos de que as nossas possibilidades, só se tansformarão na esplêndida realidade por que há tanto tempo ansiamos, se trabalharmos diuturnamente, cavando de sol a sol, com inteligência e patriotismo, os caminhos da nossa grandeza.

O Estado, mero espectador da vida nacional, desapareceu na poeira dos tempos. Ao Estado moderno cabe agora a pesada tarefa do desenvolvimento econômico da nação. 
Grave, portanto, é a nossa responsabilidade. Nós somos o instrumento com que o poder público se propõe a assegurar a prosperidade e a paz nacional. Nós, os que estudamos e praticamos a administração pública, e por isto não estamos dispostos a criar uma casta de sábios iluminados a serviço de uma ciência nova, não estamos dispostos a incorrer nos êrros do passado, cercando uma técnica que veio para simplificar, de pedantismos e excentricidades, dando lugar ao aparecimento do retórico da administração, de anel no dedo, fala empolada, nostálgico como os bacharéis de outrora, sonhando hoje com as parfeições administrativas de velhas nações, como ontem sonhavam com os sistemas jurídicos perfeitos que em vão tentaram introduzir no Brasil. Sabemos muito bem que a administração pública para ser eficiente precisa de adaptar-se à cultura de cada povo, às suas condições econômicas e sociais. Como decorrência disto só auscultando os anseios do país, medindo com sensatez e modéstia a extensão de seus problemas e de suas dificuldades, é que poderemos escolher o melhor remédio, a melhor fórmula para a cura dos seus males.

Há, evidentemente, normas e regras de caráter geral que podem e devem ser aplicadas a diferentes situações, mas os detalhes, a adaptação correta só pode ser feita por quem conhece a realidade, por quem sàbiamente aliou os conhecimentos técnicos à experiência prática.

Preservamos a administração pública dos excessos com que a querem cumular os seus pretensos descobridores, transformando-a em coisa grave e misteriosa. Muito pelo contrário, a administração pública deve ser sempre a arte da simplificação das coisas a serviço do bem-estar coletivo. O país precisa de administradores públicos que tenham o senso da realidade, que conheçam os nossos problemas de perto, que saibam até que ponto é possivel aplicar esta ou aquela norma teórica que, antes de tudo, estejam dispestos a criar um sistema administrativo nosso, adaptado às nossas peculiaríssimas condições geográficas, econômicas e sociais. A reforma administrativa de que o país carece tem que ser feita saindo dessa base. Do estudo metódico das nossas condições culturais, de modo que esta reforma, de que realmente necessitamos, não se transforme em mais um amontoado de determinações legais, sem nenhuma possibilidade de aplicação prática.

Façamos da administração pública o instrumento eficiente do nosso desenvolvimento, e estaremos assegurando para o Brasil um lugar de destaque invulgar no conjunto das nações civilizadas do mundo. Mas, tenhamos sempre em mente que o bom administrador é o homem prático, objetivo e conhecedor da realidade, que com bom senso, critério e apurada formação técnica coloca a sua inteligência e o seu patriotismo a serviço de sua pátria. $\mathrm{E}$ não tenham dúvidas, do mais humilde aos mais poderoso, todos estarão contribuindo para o nosso progresso, todos estarão contribuindo para organizarmos definitivamente a vida nacional que, assentada em bases mais racionais e mais justas, irá assegurar a todos os brasileiros um mínimo de confôrto, de segurança e de tranqüilidade.

A aciministração pública não é invento nem criação particular dêsse ou daquele povo. A administração pública é o único instrumento de que pode 
lançar mão o Estado moderno, sobrecarregado de responsabilidades e deveres, para realizar as tarefas imensas de que foi incumbido. Mais do que qualquer outra atividade social, precisa a administração pública estar intima mente ligada às bases culturais da nação, já que ela só será útil e eficiente na medida em que se ajustar a essas condições próprias de desenvolvimento. Sejanios, portanto, os pesquisadores atentos e dedicados da realidade, estudemo: com atenção as nossas caracteristicas, as nossas tendências, as influências fundamentais do clima, da geografia e da economia na formação do povo brasileiro, e estaremos nos preparando para o exercicio de nossas funções com muito mais proveito do que se estivéssemos, como outrora, preocupados exclusivamente com os exemplos de fora, com o que se está fazendo nesse ou naquele país. Preocupemonos com o que nós estamos fazendo, ou o que é melhor, com o que nós estamos deixando de fazer, con o que nós já deveriamos ter feito para assegurar às gerações próximas uma vida mais tranqüila e mais respeitada. Não há povo nem raça pior ou melhor. Há povos mais pobres, mais doentes e mais atrasados. Há povòs econômicamente mais evoluídos, com melhores condições de trabalho, de estudo e de educação. O dia que dermos ao povo brasileiro as mesmas condiçôes de vida dos chamados povos adiantados do mundo, nós também surpreenderemos a todos. Tudo se resume em organizar o trabalho nacional e colocá-lo a serviço do desenvolvimento econômico. Criar a estrutura das grandes nações, abrindo estradas, construindo barragens, explorando nossos petróleo e interiorizando a Capital. Com as novas estradas o escoamento da produção, a circulação livre e desembaraçada da riqueza. Com as usinas hidreléctricas a possibilidades de novas industrias, de melhores salários e de vida melhor. Com o petróleo a indepedência econômica. Com a interiorização da Capital a conquista efetiva do Brasil, a revolução na mentalidade das classes dirigentes que, assoberbadas com os problemas do asfalto, se esquecem do interior, das imensidões perdidas de nossa pátria. Sem a mudança da Capital jamais se faria a marcha para o oeste e, mais depressa do que inaginamos, teríamos a pátria dividida em duas, a rica e a pobre, a próspera e a miserável, e pais nenhum resistiria integro a essa escandalosa injustiça.

Assentadas as bases do nosso desenvolvimento, o problema agora é um só. E' um problema de fé. De um lado os pessimistas, os que vivem amargurando, aflitos o desencadear da borrasca. Os céticos, os que vêm fantasmas em todos os cantos, aos desalentados, os fracos e os mediocres, que em vão tentam confundir seus problemas, suas dificuldades pessoais, suas frustrações e seus fracassos, com os problemas e as lutas do $\mathrm{pa}^{\mathrm{a}} \mathrm{s}$.

De outro lado estão vocês, meus amigos, que deixando nos lares distantes as famílias, os interêsses e os entes queridos, aqui vieram reafirmar a fé nos destinos do Brasil. Aqui vieram trazendo a valiosa experiên cia de cada um, adquirida na luta diária, na labuta constante, na sucessão dos poblemas permanentes que afligem os nosso administradores. Vocês não vieram para cá trazendo o espírito harmonizado, a cultura certa, ou a idéia perfeita dos nosso problemas. Não vieram com grandes conhecimentos teóricos, é bem verdade, a dureza da luta por certo não permitiu 
os devaneios literários das horas tranqüilas de ócio. Mas graças a Deus, no espirito de cada um veio intacta a imagem da nossa realidade, o conhecimento e a consciência das dificuldades do país, sentidas na própria carne, já que agora pulsam juntos, afinados pelos mesmos ideais, o coração do povo e o coração da pátria. Os responsáveis pela coisa pública não são mais aquêles exemplares exóticos e deslocados que compunham a elite de "doutores ou bacharéis de farda", de que fala Gilberto Freire. Essa falsa elite, sem vínculos com a nossa terra, procurava formar bacharéis até em agronomia, a ponto de ensinar a moços, recém-formados, métodos agrícolas abstratos e acadêmicos, importados da Europa e dos Estados Unicios.

Em todos os setores da vida nacional a mesma abstração, o mesmo entendimento precário do problema. Os nossos oficiais do exército e da marinha eram mandados estudar na Alemanha ou na França e não haveria de ser em países tão diferentes do nosso que iriamos aprender algo de útil e de prático.

$\mathrm{Na}$ verdade aprendemos muito pouco e criamos nas classes armadas da época, principalmente na marinha, perigoso desnível cultural entre comandantes e comandados, "bacharéis de farda", incompreendidos e mal vistos pela massa ignorante dos soldados rasos e marinheiros.

$\mathrm{Na}$ indústria a mesma dificuldade. Quem como o grande Mauá procurava romper a barreira de indiferença pelos problemas econômicos, era temido e tido como aventureiro, homem de "exageros industrialistas, ou excessos progressistas", ainda segundo o testemunho de Gilberto Freire.

Não havia no Brasil uma classe média organizada.

Ou a elite distante e teórica, ou a massa analfabeta. Ou o conhecimento errado, os métodos de educação inteiramente desaconselháveis, ou a completa cegueira de homens abandonados, colocados à margem da vida.

Mas, com o progresso da indústria, com o desenvolvimento vigoroso e inajelável do papel do Estado, floresceu a classe média, que seria o ponto de ecuilibrbio da nossa vida econômica e social. Com ela o Brasil se reencontrou, iniciando o processo de nacionalização da nossa cultura, dos nossos métodos de trabalho e de produção. A classe média formada por remanescentes das elites sem base, que cedo se desintegraram e por elementos melhores e mais capazes da subestrutura que se alterava, veio, por fôrça desta sintese social, com outras idéias, outros padrões e outros valores. E' esta classe média hoje, em grande parte, responsável pela administração pública no Brasil, que deverá imprimir os rumos novos à vida nacional. Nada de teorias importadas, de normas complexas, de conclusões graves e misteriosas. Só será bom o que fôr útil, só será procurado e desejado o que fôr eficiente, o que atender de modo prático às necessidades do país. Muito entusiasmo, meus amigos, muito trabalho, muito bom senso e muita tenacidade e, dentro em breve, estaremos dizendo nós mesmos, ou pelo coração de nossos filhos agradecidos: a luta foi dura, árdua e espinhosa a caminhada, ma sem nenhum momento perdemos a fé em nós mesmos e em nossa pátria. 